\title{
TÉCNICAS DE RECONHECIMENTO DE PADRÃO APLICADO A MODELO DIGITAL DE TERRENO E INFLUÊNCIAS PARA O ESCOAMENTO DO VENTO
}

\author{
Luiza Cintra Fernandes - luizacintraf@gmail.com \\ Universidade Federal de Itajubá
}

Arcilan T. Assireu - assireu@gmail.com

Universidade Federal de Itajubá 


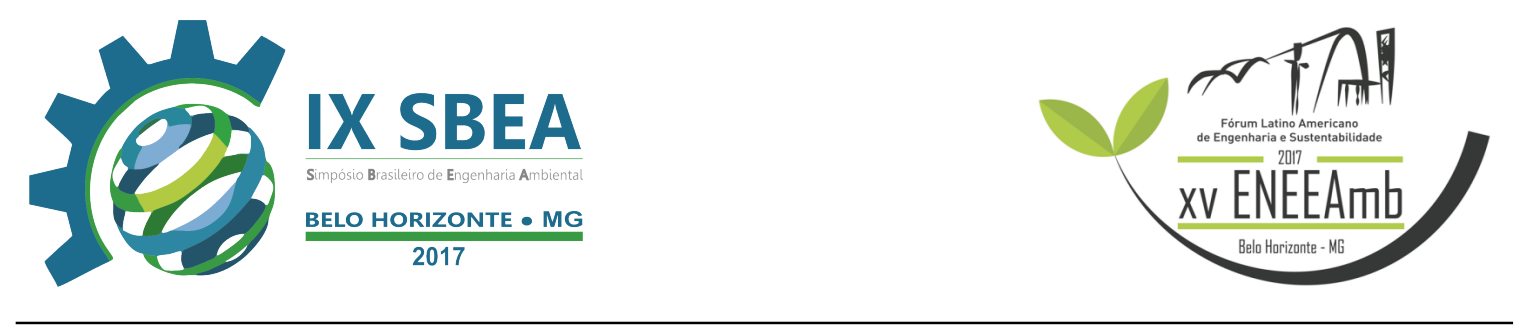

1. RESUMO

Existe uma modificação do escoamento do vento pela ação do relevo, isso ocorre por causa de um predomínio de regime turbulento nos níveis mais baixos da atmosfera. Sabe-se que o aproveitamento eólico no Brasil se dá principalmente em regiões planas e litorâneas, e devido à indisponibilidade de novas áreas para futuros investimentos, há um estudo para aproveitar regiões de terrenos complexos, como exemplo reservatórios de água. Este trabalho apresenta a investigação da influência do relevo para o escoamento do vento, aplicado ao reservatório de Furnas, próximo a cidade de Guapé-MG. Técnicas de reconhecimento de padrões com a investigação do uso do operador de fragmentos (GPA) foram aplicados para a quantificação da rugosidade em sistemas aquáticos e adjacências. A investigação da influência do relevo em o nível de turbulência do vento foi expressa pelo índice de turbulência. A aplicação do GPA, versão 1D, adaptada neste estudo, para aplicações sobre o MDE indicou que o método conseguiu identificar as rugosidades no terreno, mas apenas quando estas eram bem baixas ou nulas, como no caso da água, não identificando partes no terreno que apresentavam rugosidades mais ou menos expressivas. No estudo do índice de turbulência verificou-se que os valores maiores são influenciados pelo relevo, como por exemplo, a ilha; e valores menores representam os ventos que sopram da água para terra. Verificou-se também, uma correlação com os resultados do GPA e o IT, visualmente clara. Neste estudo foi possível perceber que a instalação de geradores de energia eólica dentro do reservatório, ao invés da instalação no seu entorno, pode aumentar o aproveitamento eólico.

Palavras-chave: MDE, índice de turbulência, GPA, energia eólica.

\section{INTRODUÇÃO/OBJETIVO}

A modificação dos ventos por fatores topográficos causa implicações para a compreensão dos padrões meteorológicos locais, da dispersão de poluentes e dos processos eólicos, isso ocorre por causa de um predomínio de regime turbulento nos níveis mais baixos da atmosfera (BULLARD et al, 2000).

$\mathrm{O}$ aproveitamento eólico no Brasil se dá principalmente em regiões planas e litorâneas, onde o perfil de velocidade do vento é desenvolvido e entendido. Dada a indisponibilidade de novas áreas planas para futuros investimentos, não se pode descartar 


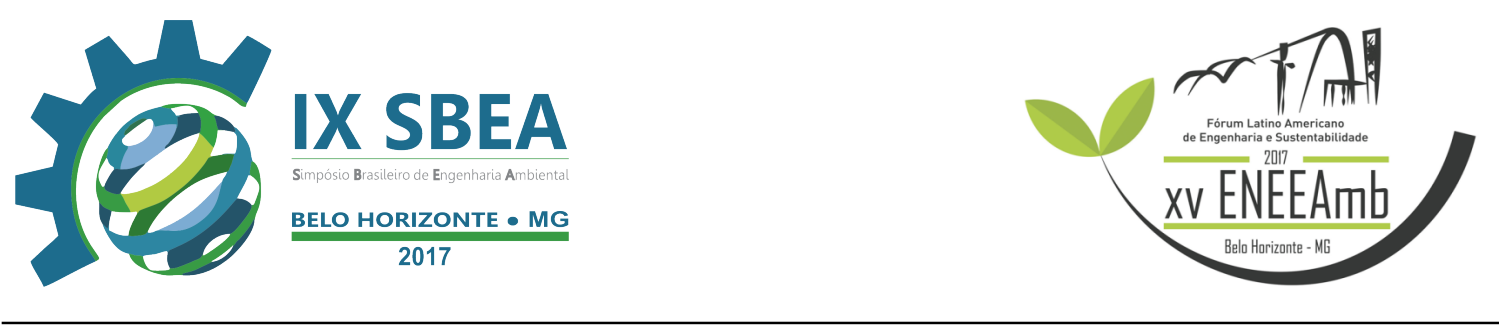

regiões em terrenos complexos. Regiões com a presença de morros, podem ter influência benéfica para a disponibilidade de energia, entretanto ocorre separação do escoamento na região de esteira fazendo com que a instabilidade do escoamento deva ser considerada como aspecto importante no aproveitamento eólico local (Mönnich e Pacheco, 2009).

Uma região pouco estudada para este fim é a região de usinas hidrelétricas. Há diferentes trabalhos abordando a dinâmica do fluxo de ar sobre lagos e outros corpos extensos de água. Nestes estudos foi descoberto que diferenças no arrasto de superfície entre a terra e corpos d'água, aliado aos efeitos da topografia complexa, leva a grandes variações espaciais de vento. E o aquecimento diferencial que ocorre entre a terra e água conduzirá à convecção e à geração de uma "brisa" de variabilidade diurna marcada. A topografia adjacente ao reservatório provoca um alinhamento e convergência do fluxo de ar, aumentando assim a direção dos ventos sobre a água e uma redução da variabilidade direcional do vento (ARCILAN,2011).

Este trabalho visa investigar a influência do relevo para o escoamento do vento, aplicado ao reservatório de Furnas, próximo a cidade de Guapé-MG. Essa investigação é feita de duas formas: a primeira emprega técnicas de reconhecimento de padrões aplicado em um Modelo Digital de Elevação (MDE), feitos a partir de imagens SRTM; a segunda aplica o índice de turbulência para investigação da influência do relevo no escoamento do vento. Isso possibilita o conhecimento sobre o nível de influência e comprometimento do relevo para o aproveitamento eólico.

\section{METODOLOGIA}

A metodologia do trabalho é dividida em duas partes: a primeira é a investigação do uso do operador de fragmentos (GPA) para a quantificação da rugosidade em sistemas aquáticos e adjacências; a segunda é a investigação da influência do relevo para o nível de turbulência do vento expressa pelo índice de turbulência.

\section{1. Área de estudo}

A área de estudo está localizada no reservatório da Usina Hidrelétrica de Furnas, próximo à cidade de Guapé, Minas Gerais. Este reservatório está localizado na Bacia do Rio Grande, sendo abastecido principalmente pelos Rio Grande e Rio Sapucaí. O reservatório possui uma extensão máxima de $220 \mathrm{~km}$, com um volume total de 22, 95 
bilhões $\mathrm{m}^{3}$, sendo uma das maiores da América Latina, possuindo uma localização privilegiada pois encontra-se perto das capitais São Paulo, Rio de Janeiro e Belo Horizonte (FURNAS).

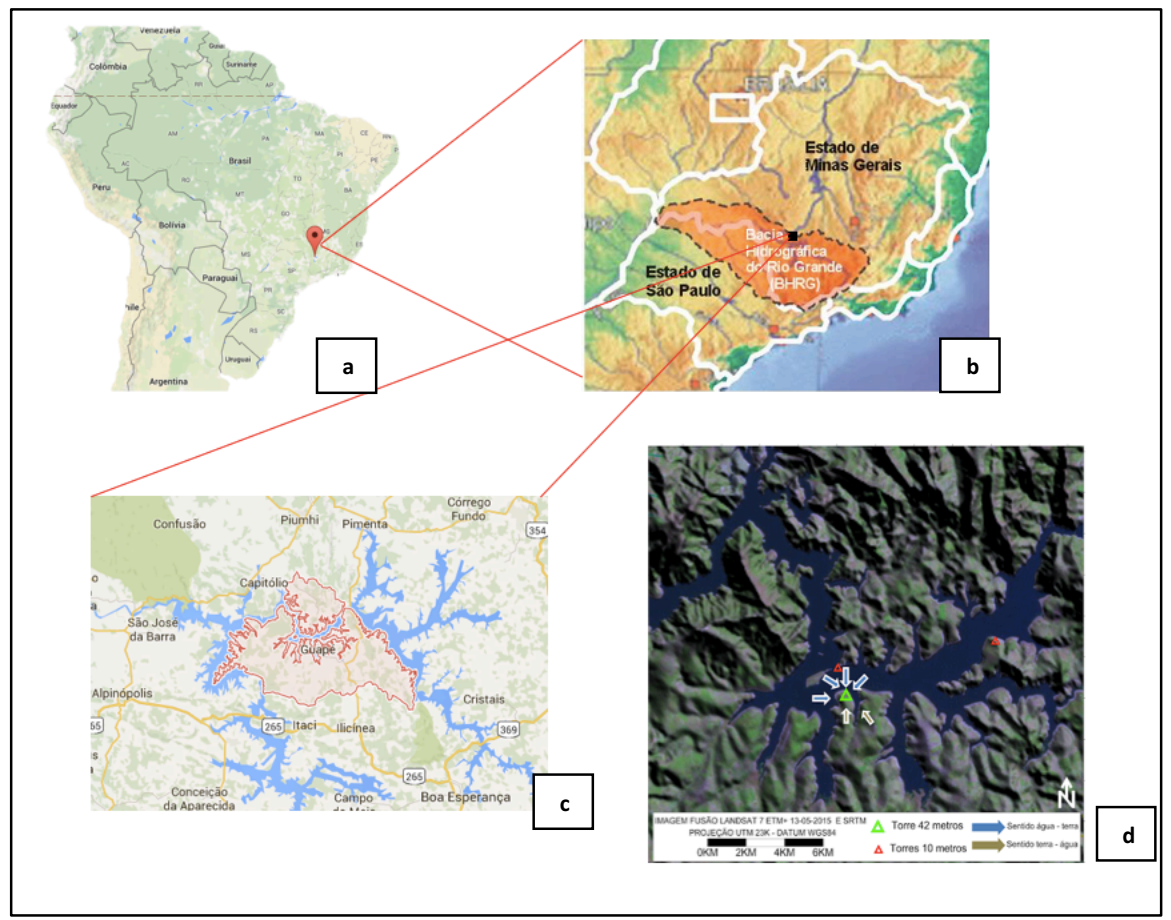

Figura 1 - Localização da área de estudo: (a) Localização no Brasil (Google Maps), (b) Localização bacia hidrográfica do Rio Grande (CBH GRANDE), (c) Localização cidade de Guapé-MG (Google Maps), (d) Localização da torre anemométrica de onde retiram os dados utilizados (Assireu, 2014).

Os dados de intensidade e direção do vento utilizados nesse trabalho são provenientes de um experimento que consistiu da instalação de três torres anemométricas instaladas no local, sendo que os dados utilizados são de uma torre de $42 \mathrm{~m}$ (triângulo verde na Figura 1d), com coordenadas de $20^{\circ} 44^{\prime}$ 26,07'S; $45^{\circ} 57^{\prime}$ 27,03'O; as medidas foram realizadas a 3, 20 e 40 m entre os dias 07/06/2014 e 14/06/2014.

O MDE utilizado no trabalho foi gerado a partir de imagens SRTM, disponibilizadas pela Empresa Brasileira de Pesquisa e Agropecuária (EMBRAPA), foi utilizada a carta SF-23-V-B que possui projeção Geográfica (Lat/Lon), com datum horizontal WGS84 e vertical EGM96, adquiridas em formato TIFF (.tif); processada no programa Global Mapper.

\subsection{Análise do Padrão de Gradientes (GPA)}




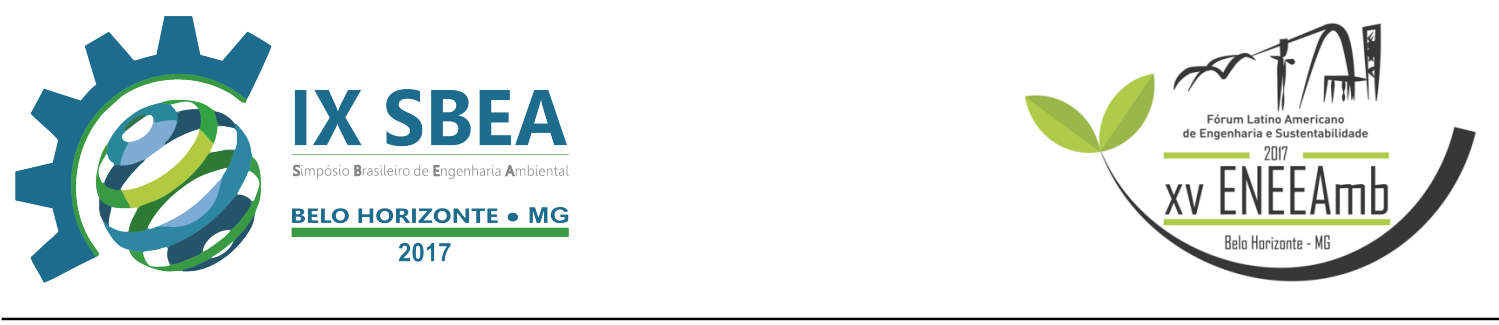

O método de análise do padrão de gradientes (GPA), introduzido por (ROSA et al 1998), realiza a investigação numérica espaço temporal complexa usando operadores computacionais. Ao contrário de outras ferramentas, o GPA não depende das propriedades estatísticas da série, mas sim da simetria dos padrões do gradiente.

O método consiste em converter a série de dados em uma sequência de matrizes $3 \times 3$. Assim, cada nove pontos da sequência de uma série, produz uma matriz $M_{X_{9}}$. A caracterização da falta de simetria e o grau de fragmentação é dada pelo operador de Fragmentação Assimétrica (FA). Sendo que esta consiste na geração de campos vetoriais a partir de matrizes numéricas, removendo vetores simétricos e mantendo apenas os vetores assimétricos (ROSA et al, 1999).

Para isso é usado o $\nabla M_{X_{9}}$ onde é associado a cada ponta da matriz um vetor. Desses vetores, eles serão simétricos se tiverem orientação oposta e assimétrico caso contrário. Assim os vetores simétricos são removidos e o número de vetores assimétricos é denotado por um valor $\boldsymbol{L}$ (ASSIREU et al, 2002). É então aplicada a Triangulação de Delaunay, que conecta os pontos dos vetores resultantes. Sendo $I$ o número de conexões geradas pela triangulação de Delaunay, quanto maior o seu número, maior a complexidade da matriz. O valor de FA é dado, portanto pela diferença de $\boldsymbol{I}$ e $\boldsymbol{L}$, normalizado por $\boldsymbol{L}$ (equação 2) (Assireu et al., 2002).

$$
\boldsymbol{F A}=\frac{(\boldsymbol{I}-\boldsymbol{L})}{\boldsymbol{L}}(\boldsymbol{I}>\boldsymbol{L}>\mathbf{0})
$$

Quando os valores de FA se aproximam de 0 apresenta uma base de dados homogênea simétrica, e valores maior ou igual a 1 refletem uma complexidade da série (CORDEIRO, 2015). Um range de valores possíveis de FA é proposto por Freitas (2012), onde é possível dividir os valores em 3 classes de assimetria: baixa (valores entre 0 e 0,6 ), média (valores entre 0,7 e 0,9 ) e alta (valores entre 1 e 1,33).

Para a aplicação do GPA, neste trabalho, foram usados os valores de cota do MDE. Para isso, a partir do MDE, foram retirados os valores de cota, com a localização partindo de um ponto de longitude fixo, varrendo todos os pontos de latitude, e assim continua para toda a dimensão do MDE, gerando os respectivos vetores. Foi desenvolvido um programa em $I D L$ que aplicado aos dados gera o FA. Para uma visualização dos resultados, os valores foram plotados em um mapa, através do Global Mapper.

\section{3.Índice de Turbulência (IT)}


O Índice de turbulência faz a medida da turbulência no escoamento do vento, sendo definida pela razão entre o desvio padrão da intensidade do vento e a intensidade média do vento, conforme Equação 3.

$$
I T=\frac{\sigma_{u}}{U}
$$

onde $\sigma_{u}$ é o desvio padrão da velocidade do vento e U a média da velocidade do vento (MANWELL, 2009).

Os valores de IT foram calculados, para dados amostrais a cada minuto, em um intervalo de 10 em 10 minutos para os dados de ventos, aplicados a um programa desenvolvido em Fortran. Os resultados foram representados em rosa dos ventos, através do programa WRPLOT, onde os dados de direção utilizados foram as medianas para cada 10 min, uma vez que a média não seria efetiva pois os valores estão em graus, e comprometeria os resultados. A rosa dos ventos também foi plotada em imagens Google Earth para melhor visualização.

\section{RESULTADOS E DISCUSSÃO}

\subsection{Aplicação do GPA para quantificação da rugosidade}

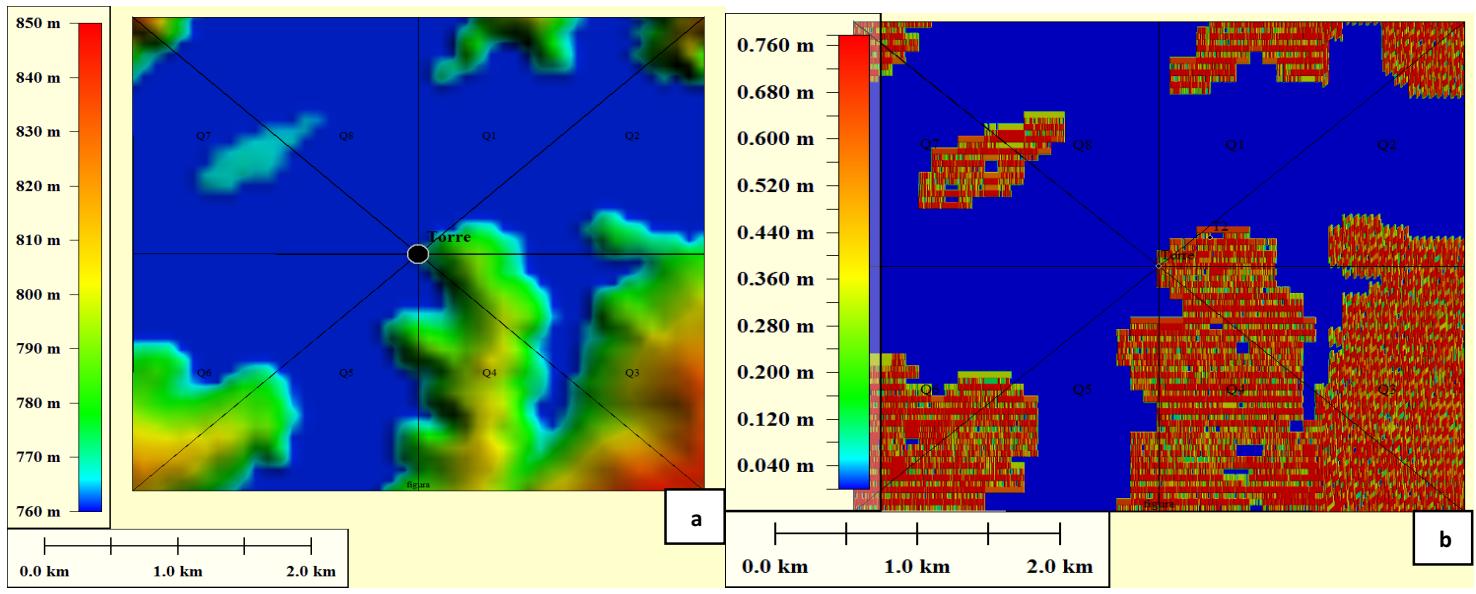

Figura 2 - (a) MDE para a área estudada (b) Resultados do GPA para a área estudada

Nota-se na figura 6 que o GPA foi eficiente para verificar a rugosidade do terreno, uma vez que a área que não apresenta rugosidade no MDE, é também a área que apresentou valores de assimetria baixos, como a região da água.

\subsection{Relação entre turbulência e rugosidade do terreno}




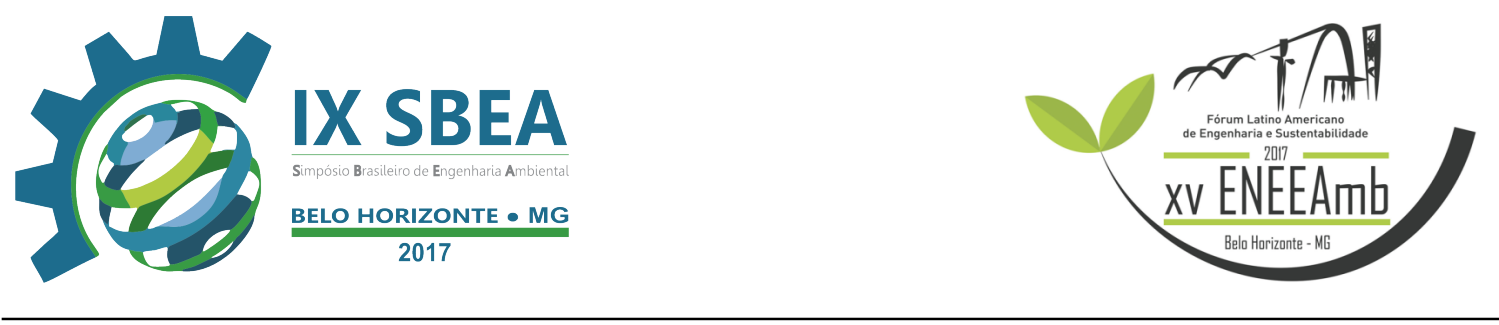

Verificou-se que o período dos dados escolhidos foi marcado por direções predominantemente diferentes: sendo que num primeiro período, entre 07/06/2014 a 10/06 de 2014, o vento estaria soprando da terra para água (chamado aqui de TA), e num segundo período, entre 10/06/2014 a 13/06/2014, da água para terra (chamado aqui de AT). A Figura 7 ilustra as séries temporais para a direção, intensidade do vento, temperatura e umidade relativa da série. As direções do vento foram divididas em setores a partir dos quais o vento intercepta a torre. Sendo que ventos entre 300 e 70 graus são aqueles do setor água (AT), e ventos entre 70 e 300 graus são do setor terra (TA). Notouse que durante os primeiros três dias, a direção do vento foi muito variável e alternou sucessivamente entre TA e AT. A partir do dia 10 de junho o vento passa a soprar mais persistentemente da água para a terra o que repercute em ventos com intensidade média maior, menor variabilidade temporal e maior cisalhamento vertical (Figura 7). Neste período também há menores amplitudes diurna de temperatura e umidade relativa.

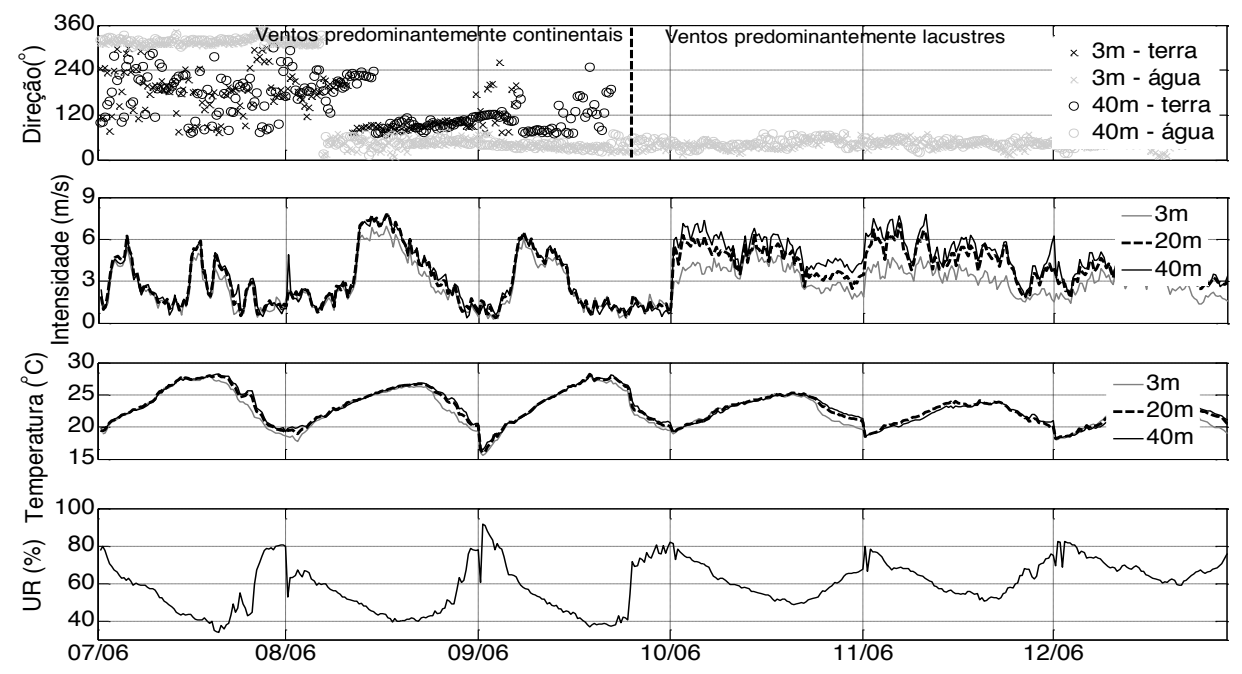

Figura 3 - Séries temporais da direção e intensidade do vento, temperatura e umidade relativa (Assireu et al, 2015).

As Figuras 8 (a) e (c) trazem a rosa dos ventos para os do setor TA e AT, respectivamente. Conforme discutido acima, os ventos do setor TA foram mais variáveis e tiveram alguma contribuição de ventos do setor noroeste, conforme visualizado na Figura 8a enquanto o vento do setor AT (Figura 8c) é basicamente de vento soprando da água.

Nota-se que os ventos de NO são mais intensos devido às influências da ilha (Figura 8a), nesta direção também se encontram ventos mais turbulentos (Figura 8b). É 

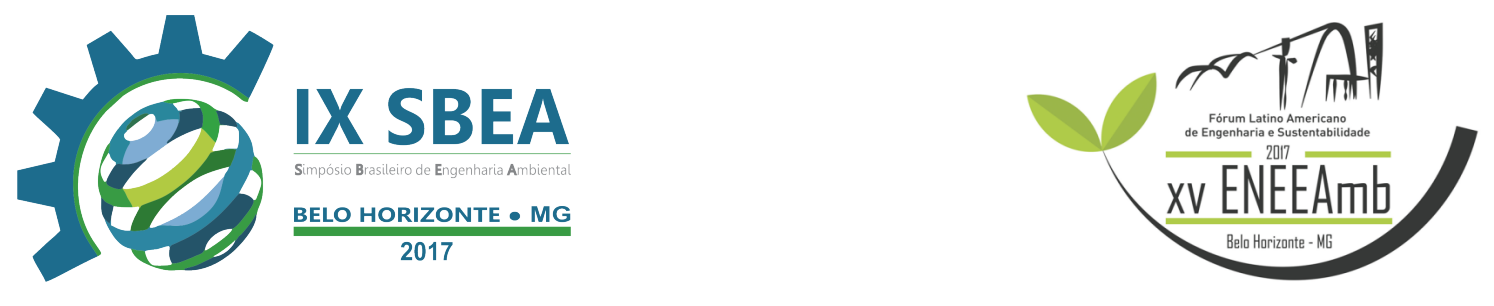

perceptível, também, que os ventos soprando de Terra para água tiveram maiores valores de IT. Enquanto que os ventos de AT tiveram menores valores de IT (Figura 8d), e predominância na direção NE, aonde há uma maior porção de água.
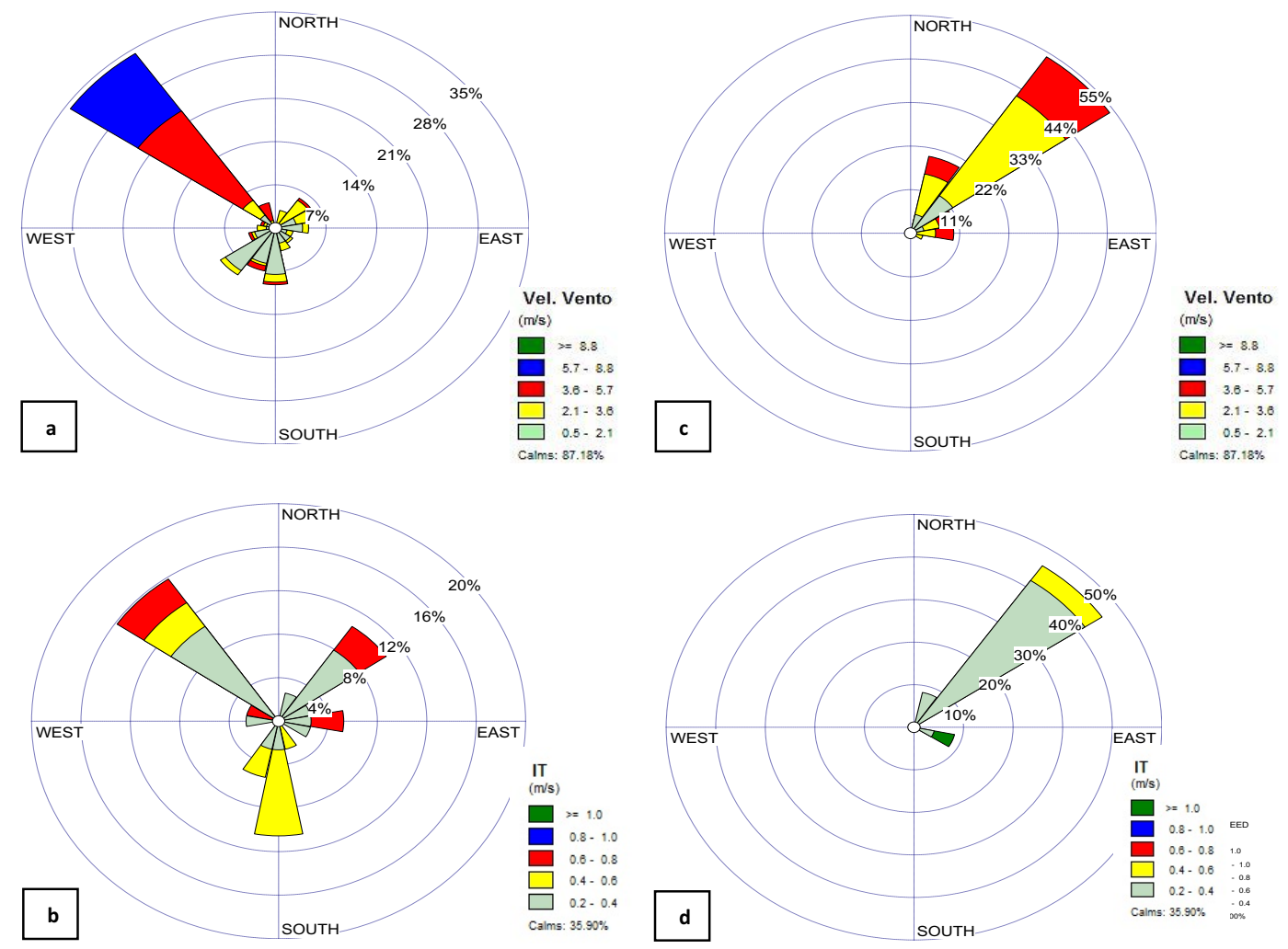

Figura 4 - Rosa dos ventos e respectiva representação na área estudada para a intensidade do vento (a) e IT (b) de TA para a altura de 3 metros. Rosa dos ventos e respectiva representação na área estudada para a intensidade do vento (c) e IT (d) de AT para a altura de 3 metros.

Para efeito de comparação foram feitas as rosas do vento para a altura de $40 \mathrm{~m}$, e percebeu-se, que para essa altura não houve influência da ilha na intensidade e turbulência dos ventos. Isto é de certa forma esperado por conta da cota da ilha $(\sim 15 \mathrm{~m})$ estar abaixo do nível de vento em questão $(40 \mathrm{~m})$. Percebe-se também que a intensidade do vento é maior nesta altura tanto pra TA e AT, mas o IT continua sendo maior para ventos soprando de terra para água.

\section{CONCLUSÕES/RECOMENDAÇÕES}




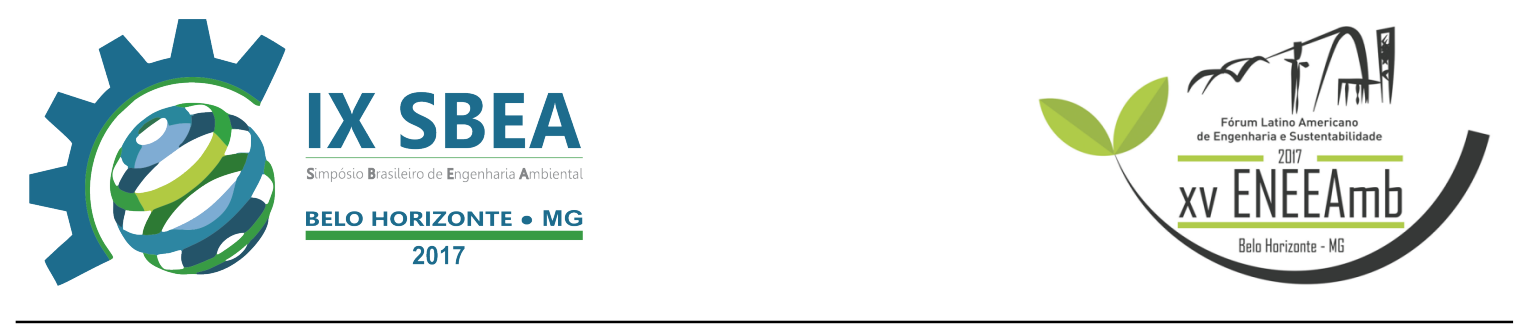

Tendo em vista investigar o efeito do terreno para o escoamento do vento e regiões de transição entre terra e água foram utilizados MDEs a partir dos dados SRTM e dados de vento medidos por uma torre de $40 \mathrm{~m}$. A aplicação do GPA, versão 1D, adaptada neste estudo, para aplicações sobre o MDE indicou que o método conseguiu identificar as rugosidades no terreno, mas apenas quando estas eram bem baixas ou nulas, como no caso da água, não identificando partes no terreno que apresentavam rugosidades mais ou menos expressivas. Sugere-se que em trabalhos futuros seja aplicado o GPA 2D bem como outras técnicas como o DFA neste tipo de análise.

Para as análises do terreno sobre o escoamento, baseado no índice de turbulência, dois períodos marcantes foram observados nos dados: num período inicial o vento alternava entre de terra para água e água para terra e, no segundo período o vento foi quase que somente de água para terra. Os resultados indicaram que para a altura de $3 \mathrm{~m}$ os ventos de NO, que sopram da água para a terra, são os mais intensos, porém mais turbulentos, devido a influência da ilha. Enquanto que os ventos soprando de água para terra, sem influência da ilha, tiveram menores valores de IT e predominância na direção NE, aonde há maior porção de água. Já na altura de 40 m não há a influência da ilha, que possui uma cota menor, e o IT continua sendo maior para ventos de terra para água. As intensidades do vento nesta altura são maiores, para ambas as direções.

No estudo do índice de turbulência verificou-se que este tem uma correlação, visualmente percebida, com os resultados do GPA. Sendo que com o estudo em conjunto dos dois foi possível inferir informações sobre a influencia da complexidade do terreno.

Com este estudo foi possível perceber que a instalação de geradores de energia eólica dentro do reservatório, ao invés de no entorno, pode aumentar o aproveitamento eólico. Também os ventos soprando da Água para a Terra apresentam baixa turbulência, o que é bom para diminuir a fadiga da turbina eólica. Percebeu-se também que em maiores alturas a intensidade do vento é maior, e como as turbinas são instaladas a grandes alturas ( $\sim 100 \mathrm{~m})$, o aproveitamento neste local poderia ser viabilizado.

\section{REFERÊNCIAS BIBLIOGRÁFICAS}

ASSIREU, A. T.; ROSA, R. R.; LORENZZETTI, J. A.; VIJAYKUMAR, N. L.; REMPEL, E. L.; RAMOS, F. M.; SÁ, L. D. A.; BOLZAN, M. J. A.; ZANANDREA, A. 
Gradient pattern analysis of short nonstationary time series: an application to Lagrangian data from satellite tracked drifters. International Journal of Modern Physica D, p.397403. 2002.

ASSIREU, A. T. PIMENTA, F.M. FREITAS, R.M. Observações e modelagem da camada limite interna no entorno de extensos sistemas aquáticos. Ciência e Natura, Santa Maria, v. 36 n. 2 jun. 2014 (aprovado para publicação).

BULLARD, J. E.; WIGGS, G.F.S.; NAHS, D. J. Experimental study of wind directional variability in the vicinity of a model valley. Geomorphology, 35, 127-143, 2000.

Cordeiro, T. L. Quantificação da complexidade do relevo e suas implicações para propriedades aerodinâmicas. Dissertação de Mestrado em Meio Ambiente e Recursos Hídricos. 65p. 2015.

EMBRAPA. Imagens SRTM para Minas Gerais. Disponível em: $<$ http://www.relevobr.cnpm.embrapa.br/download/mg/mg.htm $>$. Acessado em: $11 / 08 / 2015$

FREITAS, R. M. Laboratório virtual para visualização e caracterização do uso e cobertura da terra utilizando imagens de sensoriamento remoto. 2012. 255f. Tese (Doutorado em Computação Aplicada) - Instituto Nacional de Pesquisas Espaciais, São José dos Campos, 2012. Disponível em: <www.urlib.net/8JMKD3MGP7W/3BDRG5P>. FURNAS. Sistema Furnas de Geração e Transmissão. Disponível em: $<$ http://www.furnas.com.br/hotsites/sistemafurnas/usina_hidr_furnas.asp $>$ Acessado em: $01 / 10 / 2015$

Mönnich, K.; Pacheco, A. Brasil: Implementando um campo de teste para verificação de modelo CFD. DEWI MAGAZIN N.35, p. 18-21, 2009.

ROSA, R. R.; SHARMA, A. S.; VALDIVIA, J. A. Characterization of asymmetric fragmentation patterns in spatially extended systems. International Journal of Modern Physics C, v.10, n.01, p.147-163. 1999

ROSA, R. R.; SHARMA, A. S.; VALDIVIA, J. A. Characterization of localized turbulence in plasma extended systems. International Journal of Modern Physica A, 257, p.509-514. 1998. 